\title{
A Uninucleate Wheat-infecting Strain of the Stem Rust Fungus Isolated from Axenic Cultures
}

\author{
By D. J. MACLEAN AND K. J. SCOTT \\ Department of Botany, University of Queensland, \\ St Lucia, Queensland 4067, Australia \\ AND INEZ C. TOMMERUP \\ Department of Botany, University of Cambridge, \\ Downing Street, Cambridge, CB2 $3 E A$
}

(Accepted for publication I4 January I97I)

\section{SUMMARY}

Four monokaryotic axenic cultures derived from a dikaryotic isolate of Puccinia graminis tritici race I26-ANZ-6, 7 were tested for pathogenicity on wheat leaves. Only two rust cultures were pathogenic, one of which was propagated on wheat for six uredial generations. Cytological examination showed that cells of this culture were uninucleate and apparently haploid. This isolate may have arisen by somatic recombination.

\section{INTRODUCTION}

The growth of plant rust fungi (Uredinales) in artificial culture media (axenic culture) has now been firmly established (Scott \& Maclean, 1969). Such cultures should prove useful for biochemical, physiological, and genetical studies of the fungus and of the host-parasite system. However, first we must characterize any spontaneous variation which occurs in rusts grown in axenic culture. In some of our experiments (Maclean \& Scott, 1970), the incubation of wild-type uredospores of Puccinia graminis tritici race I26-ANZ-6, 7 on an artificial medium has given rise to colonies which are morphologically distinct from those described previously (Williams, Scott \& Kuhl, I966; Williams, Scott, Kuhl \& Maclean, I967; Bushnell, I968; Coffey, Bose \& Shaw, 1969). These colonies were isolated at an erratic and low incidence, and it was found that the mycelium consisted of uninucleate cells (Maclean \& Scott, 1970) in contrast to the bi- or multi-nucleate cells in mycelium formed after infection of wheat plants by wild-type uredospores (Nelson, Wilcoxson \& Christensen, I955). The nuclear condition and pathogenicity of four uninucleate isolates are described below.

\section{METHODS}

Wheat plants (variety: Little Club) fully susceptible to Puccinia graminis (Pers.) f. sp. tritici (Eriks. \& E. Henn.) race I26-ANZ-6,7, were grown in pots containing a sand + soil mixture in a growth cabinet ( $16 \mathrm{~h}$. light régime: 24 to $26^{\circ}$ light, $20^{\circ}$ dark). Axenic cultures of monokaryotic strains (V I, v 2, v 3 and v4) of the above race of rust were isolated and maintained as described previously (Maclean \& Scott, 1970).

Wheat leaves were inoculated with mycelium using methods similar to those of 
Williams et al. (I967). Mycelial colonies ( 3 to $5 \mathrm{~mm}$. diameter) were grown on an agar medium overlaid with Cellophane (Maclean \& Scott, 1970). After partial removal of the abaxial epidermis of primary leaves of 9 to Io day sown wheat, single fungal colonies were applied so that aerial hyphae were in contact with exposed mesophyll. The inoculum was held in position with square self-adhesive labels of the type generally used for affixing to microscope slides (Stickfast Labels Pty Ltd, Sydney, Australia). Pots containing inoculated plants were covered with polythene bags (to keep humidity high) and replaced in the growth cabinet. The polythene bags were removed after 3 to 4 days.

For cytological examination, mycelium or infected leaves were fixed in lactic acid + acetic acid + ethanol ( $\mathrm{I}+\mathrm{I}+6$, by vol.) (Singleton, I953), for $\mathrm{I} 2$ to $24 \mathrm{~h}$., then stored in $70 \%$ ethanol. Small pieces of mycelium, or frozen sections (Io $\mu \mathrm{m}$.) of infected leaves were placed in N-hydrochloric acid for $8 \mathrm{~min}$. at $60^{\circ}$, then stained by the Giemsa technique (Tommerup, 1969). Alternatively, nuclei could be observed by phase contrast microscopy in unfixed teliospores mounted in water.

Wheat leaves were inoculated with uredospores using a small, sterile scalpel or by rubbing the spores onto the leaf with clean fingers. The plants were incubated in a glass tank in the dark at $100 \%$ humidity and 22 to $23^{\circ}$ for 20 to $24 \mathrm{~h}$. Better infection with V I C uredospores often resulted if the glass tank was lined with wet filter-paper. After incubation the plants were replaced in the growth cabinet.

\section{Pathogenicity of isolates}

\section{RESULTS AND DISCUSSION}

Under natural conditions, the uninucleate state is restricted to the diploid fusion nucleus in mature teliospores formed on wheat, and to the haploid mycelium initiated by basidiospore infection of barberry (Buller, 1950). We carried out a series of tests to investigate any interaction between wheat leaves and uninucleate mycelium of $\mathrm{VI}$, $\mathrm{V} 2, \mathrm{v} 3$ and $\mathrm{v} 4$. After 6 to $\mathrm{I} 2$ days incubation, sori containing uredospores or teliospores or both ruptured the epidermis opposite an inoculum of v I or v3, but not v 2 or v4. In some sori as many as $50 \%$ of teliospores were single-celled. Isolate v 3 differed from V I in that spores took longer to develop, and most cells in the sporophore layer of $v 3$ remained sterile. The pathogencity of $v i$ and $v 3$ has been demonstrated on many leaves on at least four separate occasions; however, repeated attempts to infect wheat leaves with mycelium of $\mathrm{v} 2$ and $\mathrm{v} 4$ all failed.

Tests were made of the ability of uredospores of $v$ I formed on wheat leaves under the above conditions to infect intact wheat plants. In March 1969 uredospores were placed on the primary leaf of two plants growing in a pot containing about 30 plants. A single rust pustule was subsequently formed on one of the inoculated leaves; the non-inoculated plants remained uninfected. This isolate (designated v I C) was propagated on intact plants for 3 to 4 generations; uredospores from the later generations were used to inoculate a nutrient agar medium (Williams et al. 1967). The axenic cultures of V I C so obtained were maintained by serial subculture. Such cultures of V I C showed growth characteristics different from those of VI, the parental culture. Similar infection tests were not carried out with $v_{3}$ because few uredospores were formed after infection by the epidermis-removal method.

Experiments were performed to determine whether saprophytic mycelium of V I C 
retained pathogenicity. Wheat leaves were readily infected by the epidermis-removal method of infection. The uredospores so formed were applied to 13 leaves on intact plants of which eight developed I to 5 pustules per leaf.

Disease symptoms caused by uredospores of V I C and the wild-type were readily distinguished. For example, flecking appeared 7 to 9 days after inoculation by v I C, compared with 5 to 6 days for the wild-type. Pustules of the wild-type were more elongated and produced a greater profusion of uredospores than did V I C. Whereas wild-type infections rarely formed teliospores under the conditions in our growth cabinets, V I C infections often entered a telial stage $I$ to 3 weeks after rupture of the host epidermis.

\section{Nuclear condition}

The nuclear condition of fungal cells in plants infected by uredospores of v I C was studied. Uredospores and teliospores, together with their pedicels and stalk cells, were uninucleate at all stages of development (Pl. I, fig. I, 2), although occasional binucleate spores of each type were found. The proportion of binucleate spores varied from 0 to $3 \%$ in samples of up to 500 spores. The incidence of teliospores containing binucleate cells was about the same as that of binucleate uredospores.

In all v I C infections examined, binucleate cells were usually restricted to spores rather than to vegetative hyphae; spores containing binucleate cells were almost invariably subtended by uninucleate pedicels, and such spores did not occur in sectors; anastomosis was not detected between cells of VIC in the immediate vicinity of dikaryotic spores; occasional late mitotic division occurred in teliospores which had thick dark walls, and so appeared to be mature. This evidence is consistent with V I C being a haplont in which all nuclei are haploid and identical, but nuclear division and septation may sometimes get out of phase, with the consequent formation of spores containing two daughter nuclei. The view that V I C is a haplont is further supported by its derivation from a single pustule on a wheat leaf, the parent uredospore inoculum having arisen from a monokaryotic culture (VI). The uninucleate condition has remained stable for at least six generations of v I C propagated from plant to plant.

The specificity of heteroecious rusts for their primary or alternate host species is thought to be related to the nuclear condition of their mycelium. This idea is consistent with the results of reinfection studies carried out by Cutter (1959; Scott \& Maclean, I969) on his seven axenic isolates of Gymnosporangium juniperi-virginianae. These isolates varied in nuclear content: the number of nuclei per cell determined whether the alternate host (Pyrus) or the primary host (Juniperus) could be infected, and also determined the type of fungal fructification formed. However, this habit does not apply to our uninucleate isolate of Puccinia graminis tritici (VIC) since it is able to complete the uredial stage of development on wheat. The work of Newton \& Johnson (I939) and Buller (1950) supports our findings. They obtained abnormal strains of $P$. graminis tritici by selfing some races on barberry. Some abnormal strains were propagated on wheat plants and produced uredial sori in some of which all uredospores were uninucleate (Buller, 1950). Buller (1950) thought the uninucleate uredospores were haploid, although direct evidence was not available.

We have examined dividing nuclei of $\mathrm{VI}_{1}, \mathrm{v}_{2}, \mathrm{v}_{3}$ and $\mathrm{v}_{4}$ when grown on agar medium, of V I C and $\mathrm{V} 3$ when mycelium had invaded mesophyll cells of wheat after the epidermis had been removed, and of VIC when grown on plants infected by 
uredospores. In Giemsa-stained squashes or sections, six or approximately six chromosomes were counted per nucleus in many nuclei of each isolate. Concomitant examination of nuclei in the dikaryotic wild-type organism has also revealed $n=6$ chromosomes per nucleus, in agreement with previous work (McGinnis, I953).

Despite circumstantial evidence for the nuclear homogeneity of VIC, the status of our other monokaryotic isolates is less clear because we have recently observed binucleate sectors in saprophytic mycelium of v 2 and v 3 . At present, we are further characterizing the variant forms we have observed in our cultures. It seems possible that at least VIC could have arisen by some mechanism of somatic recombination during the isolation or maintenance of axenic cultures. This is supported by the isolation of similar variants during the selfing experiments of Newton \& Johnson (I939).

This work was supported in part by grants from the Wheat Industry Research Council of Australia, and by the Australian Research Grants Committee. D. J.M. held a Commonwealth Post-graduate Award, and I.C.T. received support from the International Federation of University Women and the South Australian Women Graduates Association.

\section{REFERENCES}

Buller, A. H. R. (1950). Researches on Fungi, vol. 7, pp. 293-296. Toronto, Canada: University of Toronto Press.

Bushnelu, W. R. (1968). In vitro development of an Australian isolate of Puccinia graminis f. sp. tritici. Phytopathology 58, 526-527.

COFFEY, M. D., BoSE, A. \& SHAW, M. (1969). In vitro growth of gelatin suspensions of uredospores of Puccinia graminis $\mathrm{f}$. sp. tritici. Canadian Journal of Botany 47, 1291-1293.

CUTTER, V. M. JUN. (1959). Studies on the isolation and growth of plant rusts in host tissue cultures and upon synthetic media. I. Gymnosporangium. Mycologia 5I, 249-295.

MCGrNNIs, R. C. (1953). Cytological studies of chromosomes of rust fungi. I. The mitotic chromosomes of Puccinia graminis. Canadian Journal of Botany 3x, 522-526.

MACLEAN, D. J. \& ScoTt, K. J. (1970). Variant forms of saprophytic mycelium grown from uredospores of Puccinia graminis f. sp. tritici. Journal of General Microbiology 64, 19-27.

Nelson, R. R., Wilcoxson, R. D. \& Christensen, J. J. (1955). Heterokaryosis as a basis for variation in Puccinia graminis var. tritici. Phytopathology 45, 639-643.

NewTon, M. \& Johnson, T. (1939). Variation and hybridization in Puccinia graminis. Proceedings of the Third International Congress for Microbiology, New York, p. 544.

SCotT, K. J. \& MACleAN, D. J. (1969). Culturing of rust fungi. Annual Review of Phytopathology 7, I23-I46.

Singleton, J. R. (1953). Chromosome morphology and the chromosome cycle in the ascus of Neurospora crassa. American Journal of Botany 40, 124-I44.

Tommerup, I. C. (1969). Studies on Some Biotrophic Fungi Associated with Heteropogon contortus. Ph.D. Thesis, University of Queensland.

Williams, P. G., Scott, K. J. \& KuHL, J. L. (1966). Vegetative growth of Puccinia graminis f. sp. tritici in vitro. Phytopathology 56, I41 8-I4I9.

Williams, P. G., SCOTT, K. J., KUHL, J. L. \& MACLEAN, D. J. (1967). Sporulation and pathogenicity of Puccinia graminis f. sp. tritici grown on an artificial medium. Phytopathology 57, 326-327.

\section{EXPLANATION OF PLATE}

Fig. I. Uninucleate uredospores of isolate vIC (Puccinia graminis tritici $)$ at different stages of development $\times 700$.

Fig. 2. Single-celled and two-celled uninucleate teliospores of isolate vic subtended by uninucleate stalk cells $\times 700$. 

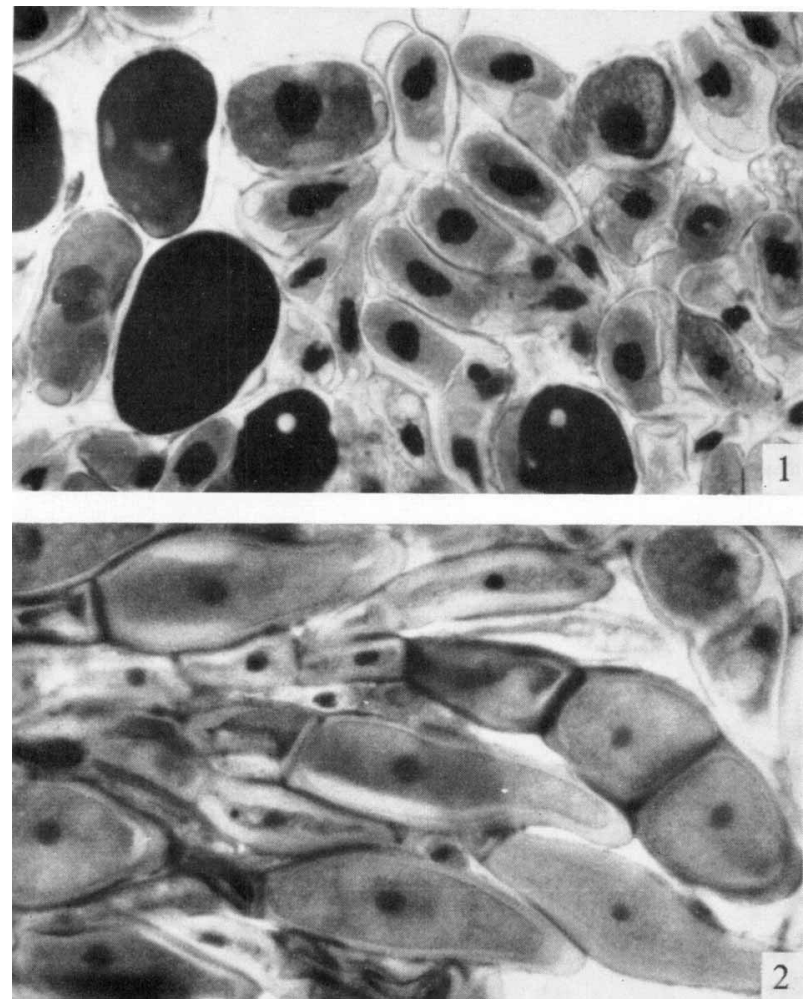